\title{
Analisis Perbandingan Metode Canny, Sobel dan HSV dalam Proses Identifikasi Bunga Anggrek Hibrida
}

\author{
Eka Candyasa Pratyaswara, Ni Kadek Ayu Wirdiani, Gusti Made Arya Sasmita \\ Program Studi Teknologi Informasi Universitas Udayana \\ Bukit Jimbaran, Bali, Indonesia, telp. (0361) 701806 \\ e-mail: ekacandyasa@gmail.com, ayuwirdiani@unud.ac.id, aryasasmita@it.unud.ac.id
}

\begin{abstract}
Abstrak
Bunga anggrek merupakan jenis bunga yang termasuk kedalam tanaman hias yang paling banyak dibudidayakan khususnya di Indonesia. Jenis bunga anggrek cukup beragam, satu jenis bunga anggrek dapat memiliki ciri berupa bentuk dan warna yang berbeda-beda, sehingga dapat membuat masyarakat kesulitan untuk dapat mengetahui jenis dari bunga anggrek tersebut. Aplikasi yang telah dibuat merupakan aplikasi yang digunakan untuk melakukan proses identifikasi terhadap beberapa jenis bunga anggrek hibrida. Aplikasi membandingkan beberapa metode yang digunakan pada proses pengenalan untuk mendapatkan metode dengan tingkat akurasi paling tinggi. Metode yang digunakan diantaranya adalah Canny Edge Detector, Sobel Edge Detector untuk mendeteksi bentuk dan metode HSV untuk mendeteksi warna. Aplikasi dibuat menggunakan platform Android sehingga lebih mudah untuk digunakan oleh masyarakat. Identifikasi dilakukan dengan pengambilan citra bunga anggrek dan dicocokkan dengan data acuan yang ada di dalam database. Uji coba dilakukan dengan sampel bunga anggrek hibrida sebanyak 54 buah dan masing-masing sampel diuji dengan ketiga metode yang sudah ditentukan. Hasil uji coba yang diperoleh adalah penggunaan metode Canny Edge Detector mendapatkan persentase keberhasilan sebesar 55.5\%, metode Sobel Edge Detector mendapatkan persentase keberhasilan sebesar $40.7 \%$ dan metode HSV mendapatkan persentase keberhasilan sebesar $70 \%$.
\end{abstract}

Kata Kunci : Anggrek Hibrida, Identifikasi , Android, Canny, Sobel, HSV

\begin{abstract}
Orchid flowers are the types of flowers that belong to the most widely cultivated ornamental plants, especially in Indonesia. Different types of orchid flowers with every one type of orchid flowers can have characteristics of different shapes and colors, so it can make people difficult to be able to know the type of orchid flowers. Applications that have been made is an application used to perform the identification process of several types of hybrid orchid flowers. The application compares some of the methods used in the recognition process to get the method with the highest degree of accuracy. Some of the methods used are Canny Edge Detector, Sobel Edge Detector to detect the shape and method of HSV to detect color. Apps are built using the Android platform making it easier for people to use. Identification is done by taking the image of orchid flowers and matched with the reference data in the database. The experiments were conducted with hybrid orchid samples of 54 pieces and each sample was tested with the three prescribed methods. The result of this experiment is the use of Canny Edge Detector method get the success percentage of 55.5\%, Sobel Edge Detector method get the success percentage of $40.7 \%$ and HSV method get the success percentage of $70 \%$.
\end{abstract}

Keywords : Hybrid Orchid Flowers, Identification, Android, Canny, Sobel, HSV

\section{Pendahuluan}

Jenis bunga anggrek pada saat ini sangat banyak dan beragam khususnya di Indonesia. Anggrek juga dapat digunakan sebagai bahan dasar untuk pengharum dan dekorasi selain untuk tanaman hias. Umumnya anggrek dapat dibedakan menjadi dua jenis utama yaitu jenis anggrek spesies dan hibrida. Anggrek spesies merupakan anggrek yang diambil langsung dari habitat aslinya sedangkan anggrek hibrida merupakan jenis bunga anggrek hasil persilangan antara dua jenis anggrek yang berbeda sehingga menghasilkan jenis anggrek baru [1].

Analisis Perbandingan Metode Canny, Sobel dan HSV dalam Proses Identifikasi Bunga Anggrek Hibrida

(Eka Candyasa Pratyaswara) 
Jenis-jenis anggrek hibrida relatif tidak mudah dikenali dikarenakan spesies yang sudah relatif banyak dan terus bertambah seiring proses persilangan. Satu jenis bunga anggrek dapat memiliki ciri berupa bentuk dan warna yang berbeda-beda, sehingga dapat membuat masyarakat kesulitan untuk dapat mengetahui jenis dari bunga anggrek tersebut. Ciri pada bunga anggrek dapat menjadi masalah karena berkaitan dengan penentuan jenis dari bunga anggrek. Masyarakat menjadi kesulitan untuk mengetahui jenis anggrek hasil persilangan yang belum diketahui, karena kemiripan ciri dengan jenis anggrek yang berbeda, ataupun sebaliknya.

Jenis anggrek hibrida memiliki beberapa ciri khusus yang digunakan sebagai kunci identifikasi sebuah bunga anggrek dibandingkan dengan bunga lainnya. Ciri yang utama pada anggrek adalah kelopak bunga atau sepal, mahkota bunga atau dapat disebut juga petal, dan juga lidah bunga yang biasa disebut dengan labellum. Bunga anggrek memiliki tiga helai sepal dan diantara sepal terdapat dua buah petal dan juga satu buah labelum. Satu jenis bunga anggrek dapat memiliki sepal, petal dan juga labellum yang berbeda-beda, selain itu warna dari satu jenis anggrek juga dapat berbeda-beda sehingga masyarakat dapat kesulitan mengenali jenis anggrek hibrida karena ciri yang kompleks untuk satu anggreknya.

Penelitian yang dilakukan oleh I Wayan Agus Suryawibawa pada tahun 2015 dengan judul "Herbs Recognition Based on Android using OpenCV" memanfaatkan beberapa metode diantaranya adalah metode Canny Edge Detector untuk melakukan pengenalan terhadap jenisjenis daun obat. Metode Canny Edge Detector digunakan untuk menemukan bentuk dari daun yang dideteksi. Aplikasi dibuat menggunakan platform smartphone dan menggunakan OpenCV. Hasil penelitian yang diperoleh dengan menggunakan metode Canny Edge Detector yaitu tingkat keberhasilan di dalam proses pencocokan cukup tinggi mencapai 79\% [2].

Teknologi pengolahan citra digital dapat menjadi solusi dalam menyelesaikan permasalahan mengenai informasi jenis anggrek yang telah dipaparkan. Pengolahan citra digital dilakukan pada penelitian ini dengan beberapa metode diantaranya Canny Edge Detector, Sobel Edge Detector dan HSV untuk tahapan pre-processing. Hasil dari tahapan preprocessing kemudian dicocokkan dengan data di dalam database, sehingga mendapatkan hasil unjuk kerja dari masing-masing metode. Hasil unjuk kerja yang telah didapatkan kemudian digunakan untuk proses analisis terhadap ciri dan metode yang paling cocok digunakan di dalam proses identifikasi bunga anggrek. Penerapan teknologi pengolahan citra digital untuk melakukan identifikasi dilakukan pada platform Android. Smartphone digunakan sebagai media utama pembuatan aplikasi karena mendukung kemudahan penggunaan, yaitu dapat digunakan kapan saja dan dimana saja sehingga mempermudah proses identifikasi pada bunga anggrek.

\section{Metodologi Penelitian}

Metodologi Penelitian adalah tahapan yang dilakukan dalam penelitian yang telah dibahas. Alur analisis sangat penting di dalam sebuah penelitian karena merupakan acuan yang digunakan dalam pengerjaan aplikasi agar sesuai dengan perencanaan yang telah dibuat. Adapun alur analisis yang dilakukan untuk pengerjaan aplikasi dijabarkan pada Gambar 1. 


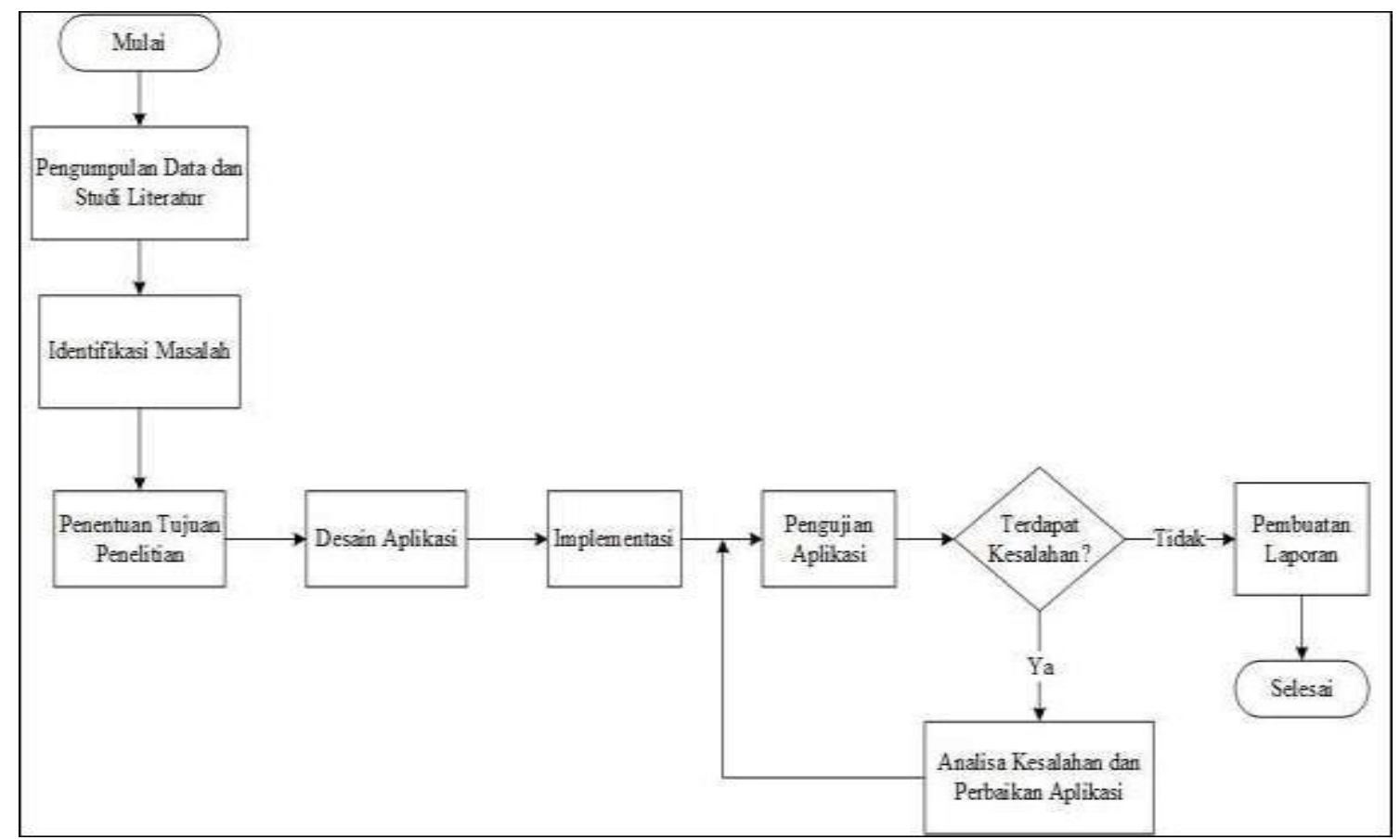

Gambar 1. Alur Analisis Penelitian

Gambar 1. merupakan tampilan dari alur analisis penelitian aplikasi yang dibuat. Alur analisis diperlukan sebagai standar proses yang dilakukan saat aplikasi dibuat, sehingga menghasilkan aplikasi yang maksimal.

\subsection{Gambaran Umum Aplikasi}

Gambaran umum proses keseluruhan dari aplikasi dapat dilihat pada Gambar 2. Gambaran umum merupakan tahapan keseluruhan proses aplikasi yang dilakukan pada sistem. Dua proses utama terdapat di dalam aplikasi, proses pendaftaran dan juga proses identifikasi.

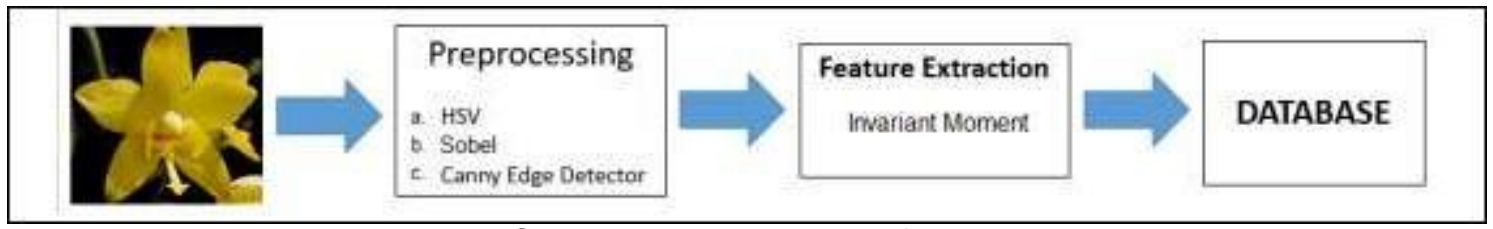

Gambar 2. Proses Pendaftaran

Proses pendaftaran citra anggrek perlu dilakukan sebelum dapat menggunakan aplikasi agar sumber data untuk melakukan proses pencocokan telah tersedia. Citra anggrek yang telah dilakukan proses capture dilanjutkan dengan proses Preprocessing. Tahapan Preprocessing menggunakan tiga metode yaitu Canny Edge Detector, Sobel Edge Detector dan juga HSV. Ketiga metode ini digunakan untuk melakukan analisa terhadap ciri dan metode yang paling tepat dalam melakukan identifikasi. Metode Invariant Moment juga digunakan untuk mendapatkan ciri dari masing-masing bunga anggrek. 


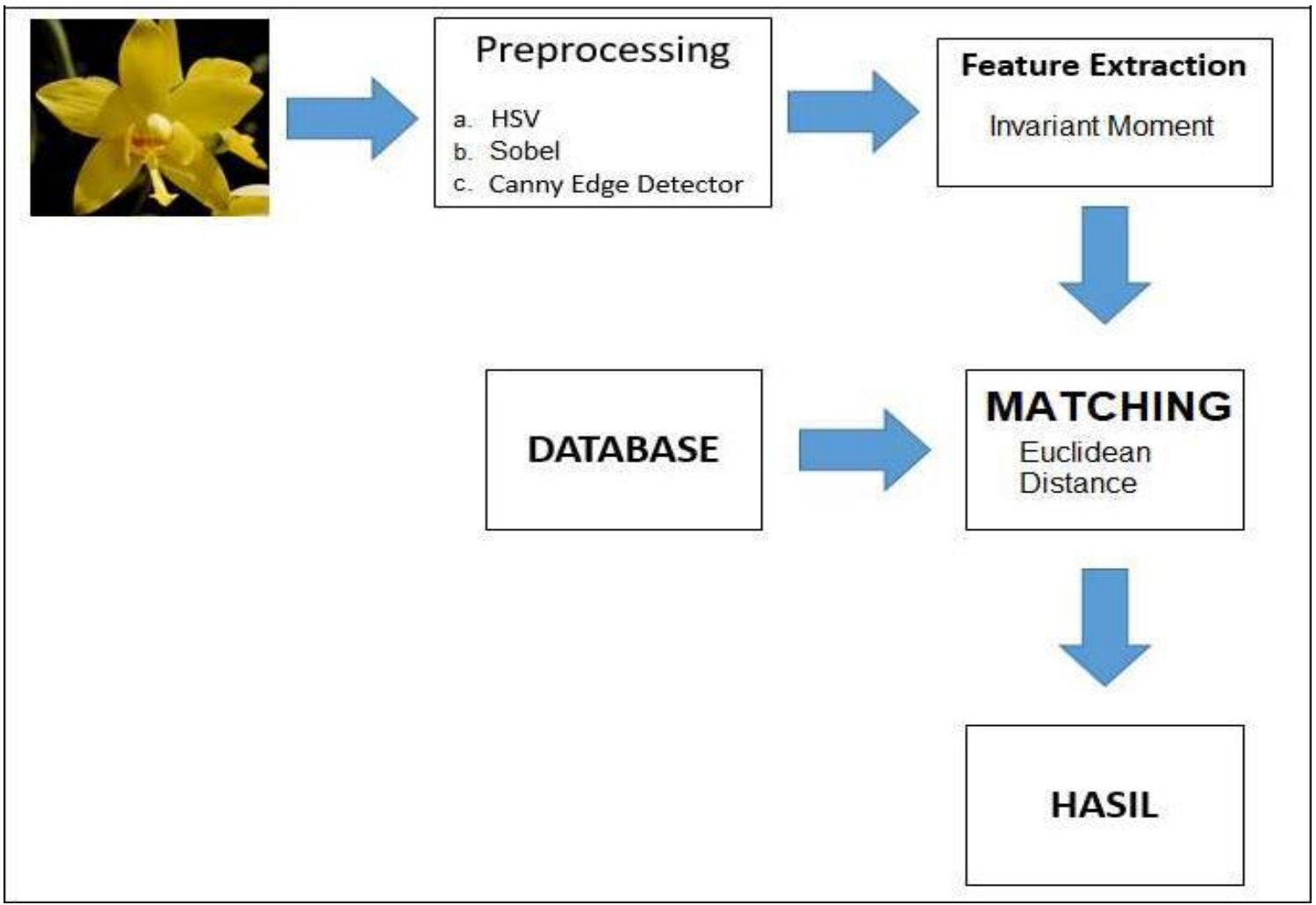

Gambar 3. Proses Identifikasi

Proses Identifikasi aplikasi yang ditunjukkan pada Gambar 3. merupakan proses pengenalan yang dilakukan dengan mengacu pada data citra bunga anggrek yang ada di dalam database. Data citra bunga anggrek yang ada di dalam database dibandingkan dengan data citra yang baru saja diambil oleh user. Aplikasi selanjutnya menampilkan hasil yang sesuai apakah citra bunga anggrek yang diambil oleh user dapat dikenali oleh aplikasi atau tidak. Bunga anggrek dapat dikenali apabila ciri dari citra bunga anggrek yang diambil terdapat di dalam database dan memiliki nilai ambang batas atau threshold yang sesuai. Beberapa modul yang digunakan di dalam aplikasi adalah sebagai berikut.

1. Image Acquisition merupakan proses pengambilan gambar. Pengambilan gambar oleh user dilakukan dengan menggunakan kamera yang ada pada smartphone maupun melakukan akses terhadap galeri. Gambar yang telah diambil dilakukan proses crop. User dapat melakukan proses crop pada gambar sesuai keinginan. Hasil proses crop dibuat menjadi gambar berukuran 150x150 piksel.

2. Preprocessing merupakan tahap selanjutnya. Tahapan preprocessing digunakan untuk melakukan proses perbaikan gambar dengan beberapa metode. Metode Canny Edge Detector, Sobel Edge Detector dan HSV digunakan pada tahapan ini. Ketiga metode tersebut digunakan dan dibandingkan tingkat keberhasilan dalam proses pencocokan untuk mendapatkan metode yang paling cocok dalam melakukan proses identifikasi.

3. Feature extraction merupakan proses ekstraksi ciri. Tahapan ekstraksi ciri dilakukan untuk mendapatkan ciri dari setiap gambar bunga anggrek yang telah diambil. Metode Invariant Moment digunakan untuk mendapatkan ciri berupa keypoint dari masingmasing gambar bunga anggrek.

4. Matching merupakan proses terakhir. Tahapan matching dilakukan dengan menerapkan metode Euclidean Distance. Metode Eucledian Distance membandingkan jarak minimum yang ada pada setiap ciri yang ditemukan pada citra anggrek.

\subsection{Flowchart Aplikasi}

Diagram alir atau flowchart yang digunakan untuk menjelaskan aliran data atau proses yang terjadi secara berurutan yang menggambarkan keseluruhan aplikasi. 


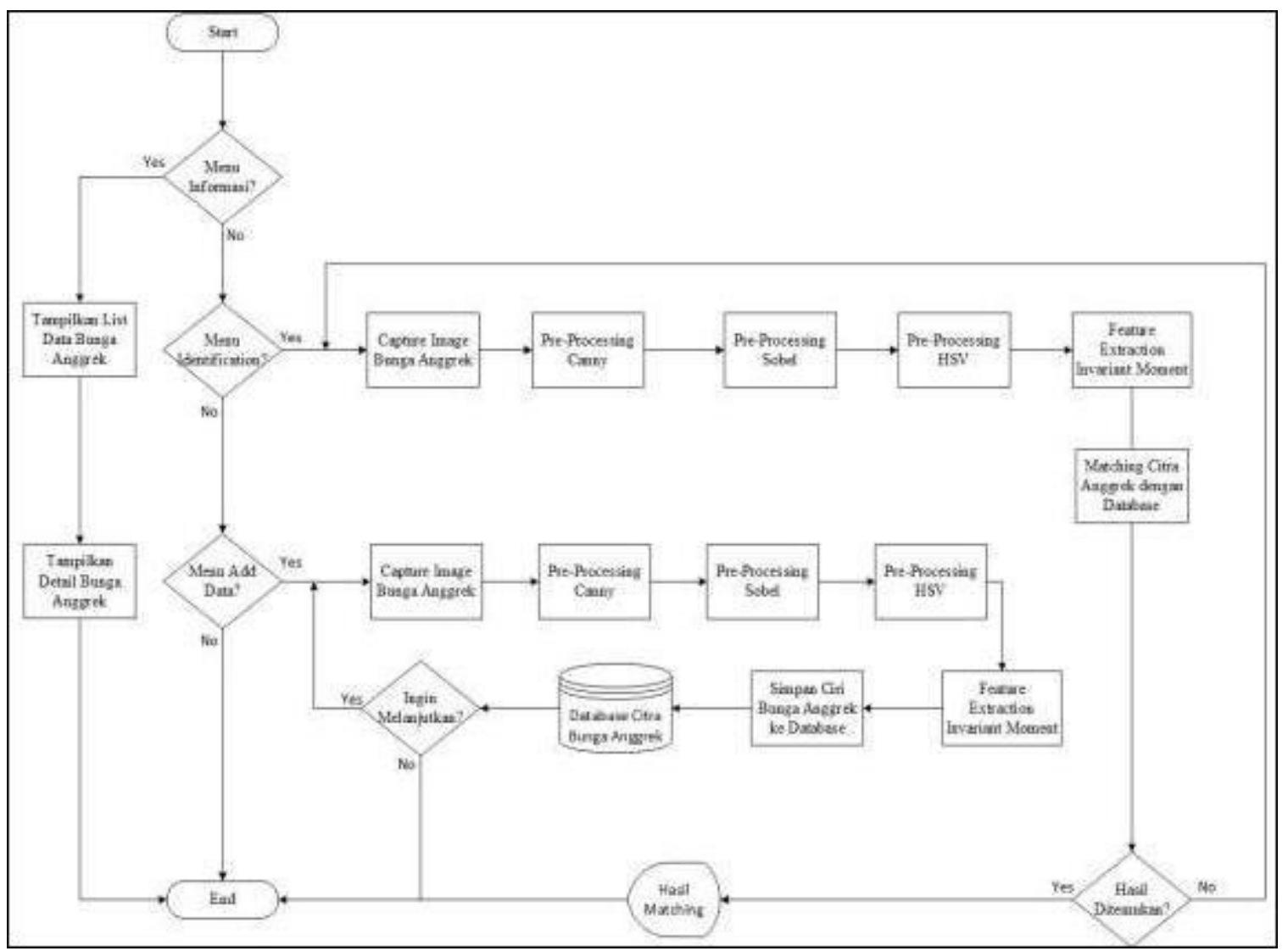

Gambar 4. Flowchart Aplikasi

Gambar 4 adalah tampilan flowchart dari keseluruhan dari aplikasi untuk melakukan identifikasi terhadap bunga anggrek. Beberapa menu disediakan diantaranya adalah menu Informasi yang memuat jenis-jenis bunga anggrek yang ada di dalam database beserta keterangannya, menu Identification yang merupakan menu utama untuk melakukan proses identifikasi bunga anggrek, dan juga menu Add Data yang memungkinkan pengguna untuk melakukan penambahan data acuan bunga anggrek ke dalam aplikasi.

\section{Kajian Pustaka}

Bab Kajian Pustaka berisikan teori pendukung yang digunakan sebagai penunjang, acuan dan yang menjadi dasar teori untuk pemecahan masalah. Beberapa teori pendukung yang digunakan untuk mendukung pembuatan aplikasi sebagai berikut.

\subsection{Anggrek}

Anggrek menjadi salah satu bunga yang paling diminati karena memiliki ciri yang beragam. Ciri tersebut menjadi keindahan tersendiri bagi bunga anggrek. Bentuk bunga yang beragam, warna bunga yang unik. Bagian bunga pada tanaman anggrek tersusun dalam sebuah karangan atau kumpulan dari banyak bunga. Bunga pada tanaman anggrek memiliki beberapa bagian penyusun utama, yaitu sepal (kelopak bunga), petal (mahkota bunga), labellum (bibir).

Bagian sepal atau kelopak pada bunga anggrek biasanya berjumlah tiga buah pada masing-masing bunga yang biasa disebut dengan dorsal sepal dan lateral sepal. Bagian petal atau mahkota biasanya berjumlah dua hingga tiga buah pada masing-masing bunga, dan terletak diantara sepal atau kelopak bunga. Bagian bunga inilah yang menjadi ciri utama dari setiap jenis anggrek, setiap anggrek memiliki kelopak, mahkota dan lidah bunga yang berbeda baik dalam bentuk, warna maupun corak pada bunga tersebut [3]. 


\subsection{Sobel Edge Detector}

Metode Sobel menggunakan dua buah kernel dalam implementasinya. Dua kernel tersebut digunakan untuk memperkirakan gradien yang ada pada arah $\mathrm{x}$ dan juga pada arah $\mathrm{y}$. Nilai gradien tersebut dihitung setiap titik atau piksel pada gambar kemudian memberi arah bagi kernel untuk terus bergerak dan meningkatkan intensitas dari citra tersebut [4].

\begin{tabular}{|c|c|c|c|c|c|}
\hline-1 & 0 & +1 & +1 & +2 & +1 \\
\hline-2 & 0 & +2 & 0 & 0 & 0 \\
\hline-1 & 0 & +1 & -1 & -2 & -1 \\
\hline \multicolumn{3}{|c|}{$\mathrm{Gx}$} & \multicolumn{3}{|c|}{ Gy } \\
\hline
\end{tabular}

Gambar 5. Kernel Sobel Edge Detector

Kernel pada Sobel Edge Detector dengan kata lain bergerak ke arah $\mathrm{x}$ dan y dan juga menunjukkan bagian mana yang merupakan tepi dari citra. Tepi dari citra yang ditemukan menggunakan kernel biasanya berwarna lebih gelap atau kontras dengan bagian yang bukan merupakan tepi [5].

\subsection{Canny Edge Detector}

Canny Edge Detector merupakan sebuah metode untuk mendeteksi garis atau tepi dari sebuah citra. Terdapat tiga buah kriteria meningkatkan metode untuk melakukan deteksi tepi [6].

1. Tingkat kesalahan yang rendah atau low error rate. Setiap tepi pada citra harus terdeteksi sebagai tepi sehingga bentuk tidak berubah.

2. Lokalisasi yang baik. Setiap jarak piksel pada tepi yang ditemukan oleh metode Canny Edge Detector dengan tepi yang sebenarnya harus minimal.

3. Frekuensi tingkat tepi yang terdeteksi secara ganda harus rendah. Ini bertujuan agar tidak menimbulkan kemungkinan yang lebih dari citra yang dideteksi.

Algoritma untuk penerapan metode Canny Edge Detector dalam memproses suatu gambar adalah sebagai berikut [7].

1. Lakukan proses filtering dengan Gaussian Filter dua dimensi agar citra yang di proses menjadi lebih halus. Gaussian Filter dua dimensi bergerak dua arah yaitu pada arah $\mathrm{x}$ dan arah y.

2. Ambil nilai gradien dari citra yang menunjukkan perubahan nilai intensitas pada tepi dari citra.

3. Lakukan proses perbandingan nilai citra menggunakan nilai gradien dengan nilai jarak antar piksel.

4. Menentukan threshold atas dan juga threshold bawah yang berguna sebagai ambang batas apakah nilai piksel tersebut dapat dikatakan sebagai tepi atau tidak.

\subsection{HSV}

HSV (Hue Saturation Value) merupakan sebuah ruang warna yang dibentuk oleh komponen hue, saturation dan value. Hue merupakan nilai warna yang ada pada derajat 0 hingga 360 [8]. Hue menunjukkan warna apa yang digunakan didalam spektrum warna. Saturation merupakan nilai keabu-abuan dari suatu warna [9]. Ruang warna saturation bernilai 0 sampai 1. Nilai 0 mewakili warna abu-abu sedangkan nilai 1 menunjukkan warna primer murni. Value merupakan ukuran yang menunjukkan tingkat kecerahan dari suatu warna. Jarak nilai pada value dapat bernilai $0 \%$ hingga $100 \%$ tergantung dari kecerahan warnanya [10].

\section{Hasil dan Pembahasan}

Bab Hasil dan Pembahasan berisi hasil dari aplikasi sistem yang sudah dibuat kemudian dilakukan pengujian hingga analisis dari hasil diperoleh. 


\subsection{Implementasi Metode}

Implementasi metode merupakan tampilan implementasi dari masing-masing metode yang digunakan. Hasil dari masing-masing metode ditampilkan berupa hasil setelah tahapan preprocessing.

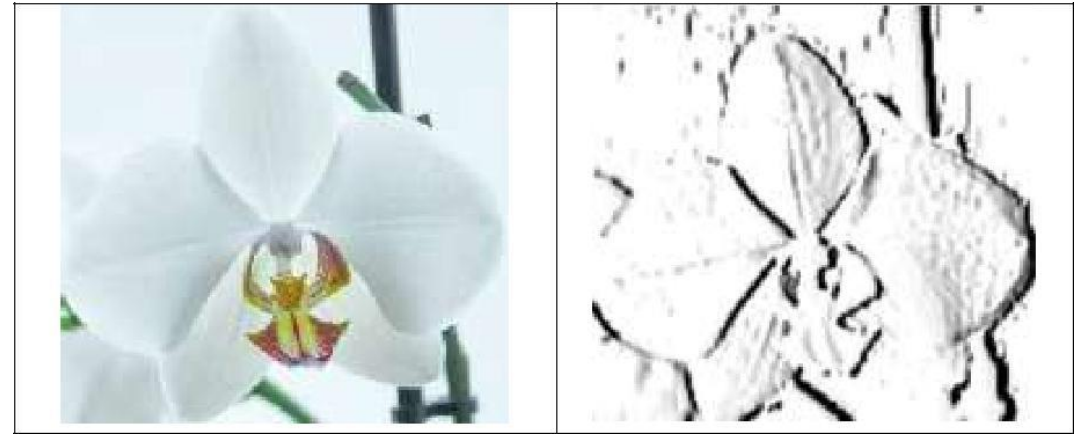

Gambar 6. Implementasi Metode Sobel Edge Detector

Gambar 6 menampilkan hasil preprocessing menggunakan metode Sobel Edge Detector. Metode Sobel membuat garis untuk setiap tepi yang terdeteksi sehingga bentuk dari citra bunga anggrek dapat diketahui.

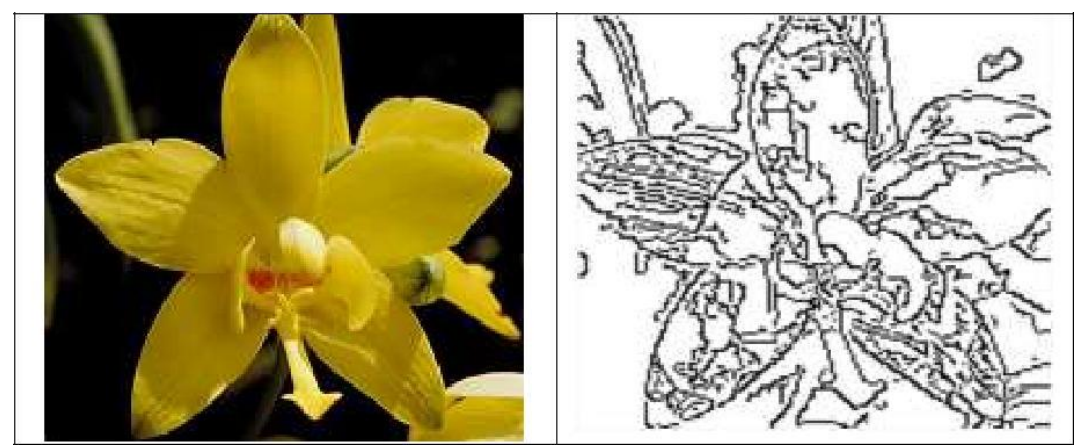

Gambar 7. Implementasi Metode Canny Edge Detector

Gambar 7 menampilkan hasil preprocessing menggunakan metode Canny Edge Detector. Metode Canny menghasilkan tepian dari citra bunga anggrek lebih lebih jelas dibandingkan metode Sobel, tetapi noise yang terbentuk juga lebih banyak sehingga perlu dikondisikan media pengambilan citra supaya noise tidak terlalu banyak tertangkap.

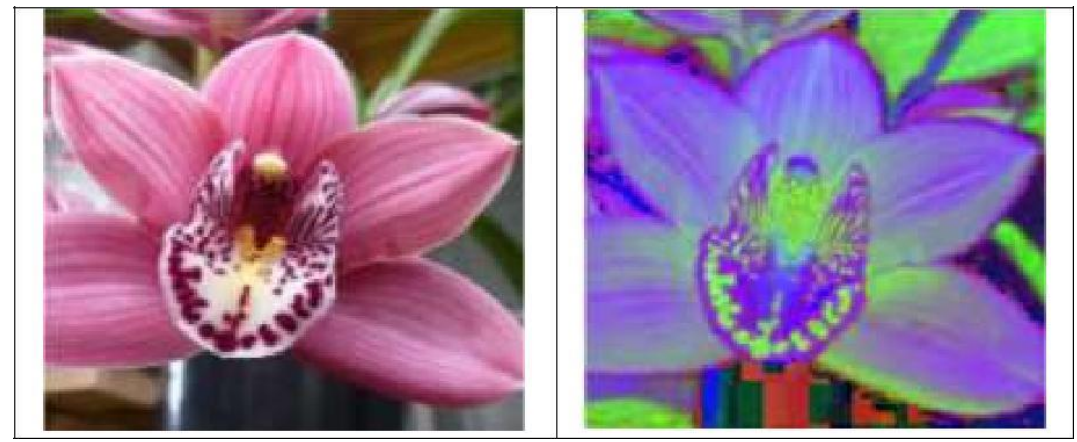

Gambar 8. Implementasi Metode HSV

Gambar 8 merupakan hasil perubahan citra bunga anggrek RGB menjadi HSV. Nilai warna HSV untuk setiap bunga anggrek berbeda sehingga menjadi acuan dalam proses pencocokan. 


\subsection{Proses Add Data}

Proses Add Data merupakan tahapan yang dapat dilakukan oleh user untuk menambahkan data bunga anggrek. Data bunga anggrek yang ditambahkan kemudian disimpan di dalam database dan menjadi acuan dalam proses identifikasi.

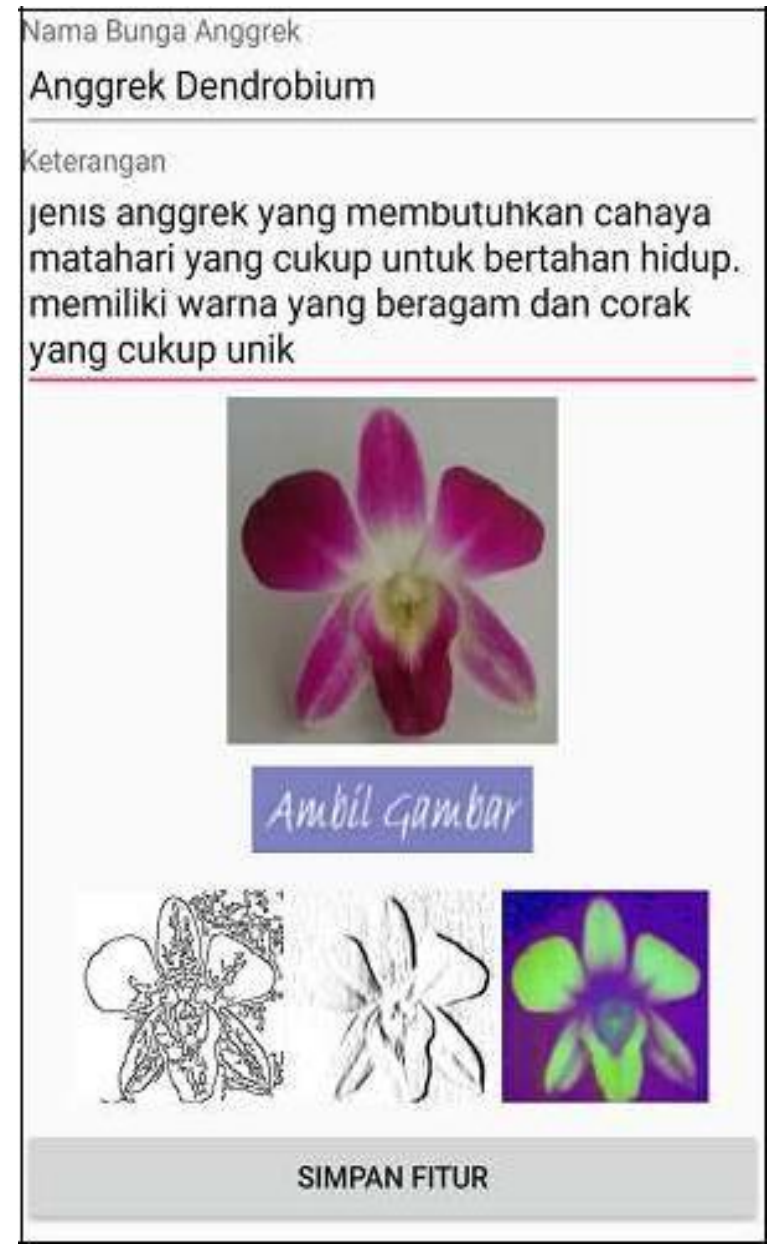

Gambar 9. Proses Add Data

Gambar 9 adalah tampilan dari proses Add Data. User harus mengisi form nama bunga anggrek dan juga keterangan dari bunga anggrek tersebut. Gambar bunga anggrek juga harus dimasukkan. Pengambilan gambar bunga anggrek dapat menggunakan kamera dari smartphone ataupun melakukan akses terhadap galeri. Data bunga anggrek yang disimpan digunakan menjadi acuan di dalam proses identifikasi.

\subsection{Proses Identifikasi}

Proses Identifikasi merupakan tahapan yang dapat dilakukan oleh user untuk melakukan proses identifikasi bunga anggrek. Proses Idetifikasi dilakukan dengan menggunakan tiga buah metode yang hasilnya dibandingkan untuk mendapatkan hasil yang maksimal. 


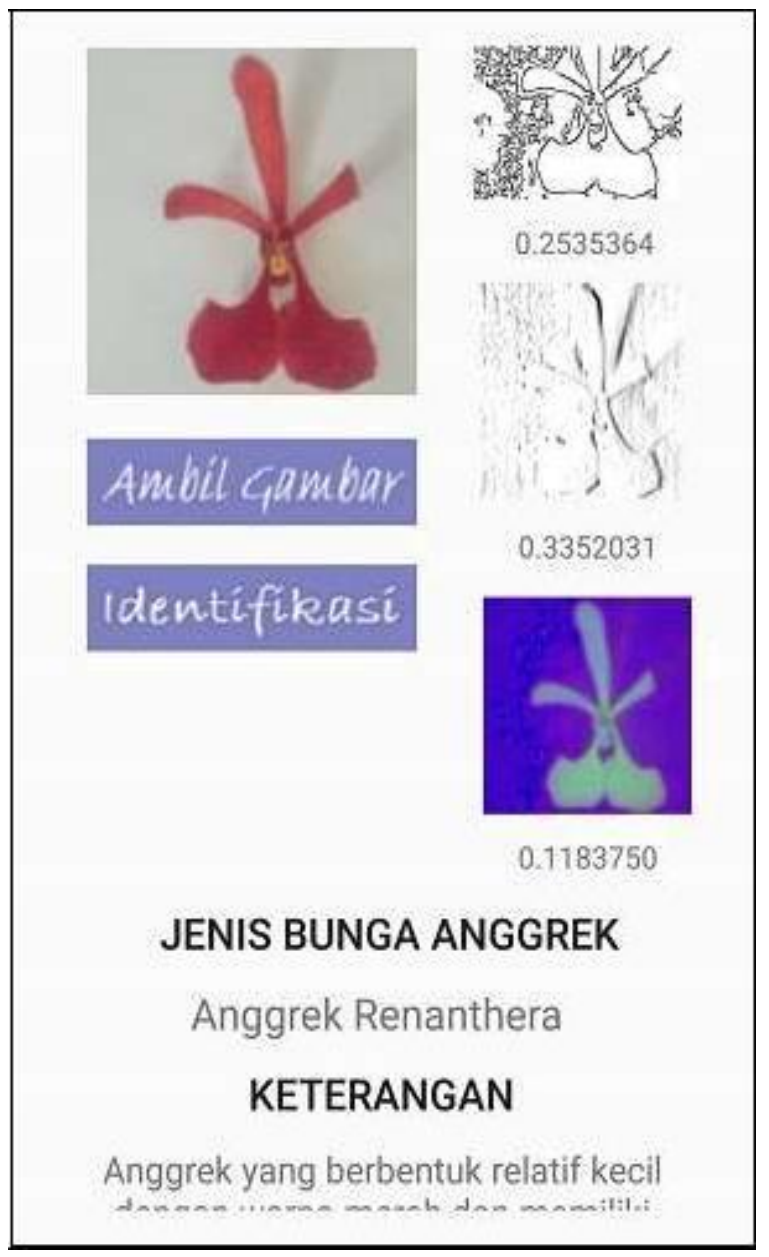

Gambar 10. Proses Identifikasi

Gambar 10 merupakan tampilan dari proses identifikasi. User harus melakukan pengambilan gambar bunga anggrek terlebih dahulu, gambar bunga anggrek kemudian dilakukan proses crop. Gambar yang telah melewati proses crop selanjutnya diproses menggunakan metode Canny, Sobel dan HSV untuk mendapatkan hasil dari proses identifikasi. Jenis anggrek yang berhasil dilakukan proses identifikasi terlihat beserta keterangan yang mengacu pada data yang ada di dalam database.

\subsection{Analisa Metode}

Analisa penggunaan metode dari penelitian aplikasi identifikasi bunga anggrek menghasilkan persentase keberhasilan dalam proses identifikasi bunga anggrek dari masingmasing metode yang digunakan.

\section{A. Analisa Metode Canny Edge Detector}

Metode Canny Edge Detector digunakan untuk mendapatkan garis yang membentuk tepian dari bunga anggrek yang dilakukan proses identifikasi. Hasil pengujian pengenalan jenis bunga anggrek menggunakan metode Canny Edge Detector ditunjukkan pada Tabel 1.

Tabel 1. Hasil Pengujian Metode Canny Edge Detector

\begin{tabular}{|l|c|c|c|c|}
\hline \multirow{2}{*}{ Nama Bunga Anggrek } & \multirow{2}{*}{\begin{tabular}{c} 
Sumlah \\
\cline { 3 - 5 }
\end{tabular}} & Sampel & \multicolumn{3}{c|}{ Hasil Pengenalan } \\
\cline { 3 - 5 } & 6 & Dikenali & Tidak Dikenali & Salah Dikenali \\
\hline Anggrek Bulan & 6 & 4 & 0 & 3 \\
\hline Anggrek Bulan Bintang & 6 & 4 & 2 & 0 \\
\hline Anggrek Sendok & 6 & 3 & 2 & 0 \\
\hline
\end{tabular}




\begin{tabular}{|l|c|c|c|c|}
\hline Anggrek Selop & 6 & 3 & 3 & 0 \\
\hline Anggrek Dendrobium & 6 & 3 & 3 & 0 \\
\hline Anggrek Coelogyne & 6 & 4 & 2 & 0 \\
\hline Anggrek Epigeneium & 6 & 3 & 3 & 0 \\
\hline Anggrek Renanthera & 6 & 3 & 3 & 5.5 \\
\hline \multicolumn{2}{|c|}{ Persentase (\%) } & 55.5 & 39 & 0 \\
\hline
\end{tabular}

Kesalahan pada proses pengenalan menggunakan metode Canny Edge Detector karena proses pengambilan gambar bunga anggrek yang dilakukan sering ditemukan noisenoise kecil yang mengganggu sehingga nilai threshold menjadi berbeda dan bunga anggrek menjadi sulit untuk dikenali.

Salah pengenalan terjadi terhadap jenis anggrek bulan. Jenis anggrek bulan memiliki bentuk yang mirip antara anggrek bulan putih dengan anggrek bulan warna lainnya, sehingga saat dilakukan proses pengenalan anggrek bulan, tidak dapat dibedakan apakah bentuk tersebut termasuk anggrek bulan dengan warna yang berbeda.

\section{B. Analisa Metode Sobel Edge Detector}

Metode Sobel Edge Detector digunakan untuk mendapatkan bentuk dan juga tekstur dari bunga anggrek yang dilakukan proses identifikasi. Hasil pengujian pengenalan jenis bunga anggrek menggunakan metode Sobel Edge Detector ditunjukkan pada Tabel 2.

Tabel 2. Hasil Pengujian Metode Sobel Edge Detector

\begin{tabular}{|c|c|c|c|c|}
\hline \multirow{2}{*}{ Nama Bunga Anggrek } & \multirow{2}{*}{$\begin{array}{l}\text { Jumlah } \\
\text { Sampel }\end{array}$} & \multicolumn{3}{|c|}{ Hasil Pengenalan } \\
\hline & & Dikenali & Tidak Dikenali & Salah Dikenali \\
\hline Anggrek Bulan & 6 & 2 & 4 & 0 \\
\hline Anggrek Bulan Bintang & 6 & 2 & 4 & 0 \\
\hline Anggrek Sendok & 6 & 3 & 3 & 0 \\
\hline Anggrek Macan & 6 & 2 & 4 & 0 \\
\hline Anggrek Selop & 6 & 2 & 4 & 0 \\
\hline Anggrek Dendrobium & 6 & 2 & 4 & 0 \\
\hline Anggrek Coelogyne & 6 & 3 & 3 & 0 \\
\hline Anggrek Epigeneium & 6 & 3 & 3 & 0 \\
\hline Anggrek Renanthera & 6 & 3 & 3 & 0 \\
\hline Persentase $(\%$ & & 40.7 & 59.3 & 0 \\
\hline
\end{tabular}

Perolehan tingkat keberhasilan yang relatif kecil disebabkan metode Sobel Edge Detector menghasilkan hasil citra yang sedikit buram dan tidak terlalu menggambarkan bentuk dari bunga anggrek. Posisi pengambilan citra dan juga noise cahaya yang masuk sangat mempengaruhi hasil pencocokan bunga anggrek, karena dengan adanya noise tersebut maka nilai threshold yang didapatkan menjadi berbeda jauh sehingga bunga anggrek menjadi tidak dapat dikenali.

\section{Analisa Metode Sobel Edge Detector}

Metode HSV digunakan untuk mendapatkan ciri berupa warna dari bunga anggrek yang dilakukan proses identifikasi. Hasil pengujian pengenalan jenis bunga anggrek menggunakan metode HSV ditunjukkan pada Tabel 3.

Tabel 3. Hasil Pengujian Metode HSV

\begin{tabular}{|c|c|c|c|c|}
\hline \multirow{2}{*}{ Nama Bunga Anggrek } & \multirow{2}{*}{$\begin{array}{l}\text { Jumlah } \\
\text { Sampel }\end{array}$} & \multicolumn{3}{|c|}{ Hasil Pengenalan } \\
\hline & & Dikenali & Tidak Dikenali & Salah Dikenali \\
\hline Anggrek Bulan & 6 & 5 & 1 & 0 \\
\hline Anggrek Bulan Bintang & 6 & 4 & 2 & 0 \\
\hline Anggrek Sendok & 6 & 5 & 1 & 0 \\
\hline Anggrek Macan & 6 & 4 & 2 & 0 \\
\hline Anggrek Selop & 6 & 4 & 2 & 0 \\
\hline Anggrek Dendrobium & 6 & 4 & 2 & 0 \\
\hline
\end{tabular}

Analisis Perbandingan Metode Canny, Sobel dan HSV dalam Proses Identifikasi Bunga 182 


\begin{tabular}{|l|c|c|c|c|}
\hline Anggrek Coelogyne & 6 & 4 & 2 & 0 \\
\hline Anggrek Epigeneium & 6 & 4 & 2 & 0 \\
\hline Anggrek Renanthera & 6 & 4 & 2 & 0 \\
\hline \multicolumn{2}{|c|}{ Persentase (\%) } & 70 & 30 & 0 \\
\hline
\end{tabular}

Penggunaan metode HSV untuk melakukan pencocokan terhadap ciri warna mendapatkan persentase tingkat keberhasilan paling tinggi dibandingkan dua metode lainnya. Metode HSV dikatakan efektif sebagai metode untuk pengenalan menggunakan ciri warna karena mendapatkan tingkat keberhasilan yang cukup tinggi. Kesalahan pengenalan terjadi pada data sampel bunga anggrek yang tingkat kecerahan pada saat pengambilan gambarnya sedikit buruk, sehingga mengakibatkan kesalahan pada proses pencocokan karena nilai threshold yang berbeda.

\section{Kesimpulan}

Aplikasi untuk melakukan identifikasi terhadap jenis bunga anggrek hibrida yang dihasilkan, menerapkan tiga buah metode utama yaitu Canny Edge Detector, Sobel Edge Detector dan juga HSV. Penggunaan metode Canny Edge Detector dan Sobel Edge Detector memanfaatkan ciri berupa bentuk dan tekstur dalam melakukan proses identifikasi, sedangkan metode HSV memanfaatkan ciri berupa warna dari bunga anggrek yang dilakukan proses identifikasi. Tingkat keberhasilan yang didapatkan dari masing-masing metode bervariasi. Metode Canny Edge Detector mendapatkan tingkat keberhasilan dalam proses identifikasi sebesar 55.5\%. Metode Sobel Edge Detector mendapatkan tingkat keberhasilan dalam proses identifikasi sebesar 40.7\%. Metode HSV mendapatkan tingkat keberhasilan dalam proses identifikasi sebesar 70\%. Tingkat keberhasilan pencocokan dengan metode HSV menjadi tingkat keberhasilan paling tinggi dibandingkan dengan kedua metode lainnya, sehingga metode dan ciri yang menunjukkan unjuk kerja paling baik dalam proses identifikasi adalah ciri warna dari bunga anggrek dengan menggunakan metode HSV.

\section{DAFTAR PUSTAKA}

[1] Darmono, "Kiat Merawat Anggrek". Depok : Penebar Swadaya, 2010.

[2] I. Agus Suryawibawa, I. Gede Darma Putra, N. Ayu Wirdiani, "Herbs Recognition Based on Android using OpenCV," International Journal of Image, Graphic and Signal Processing., vol. 7, no. 2, pp. 1-7, 2015.

[3] N. R. Djuita , S. Sudarmiyati, H. Candra, Sarifah, S. Nurlaili, R. Fathony, "Keragaman Anggrek di Situ Gunung Sukabumi," Biodiversitas., vol. 5, no. 2, pp. 77-80, 2004.

[4] S. Vijayarani, M. Vinupriya, "Performance Analysis of Canny and Sobel Edge Detection Algorithms in Image Mining," International Journal of Innovative Research in Computer and Communication Engineering., vol. 1, no. 8, pp. 1760-1767, 2013.

[5] Smita Patil, Shridevi Soma, Suvarna Nandyal, " Identification of Growth Rate of Plant based on leaf features using Digital Image Processing Techniques," International Journal of Emerging Technology and Advance Engineering., vol. 3, no. 8, pp. 266-275, 2013.

[6] A. D. Chitra, P. Ponmuthuramalingam, "An Approach for Canny Edge Detection Algorithm on Face Recognition," International Journal of Science and Research., vol. 4, no. 11, pp. 24-27, 2015.

[7] M. D. Mulyawan, N. M. Ika Mandenni, G. M. Arya Sasmita, "Application of Coconut Recognition Using Laplacian and HSV based on Android," International Journal of Application or Innovation in Engineering \& Management., vol. 7, no. 7, 2017.

[8] I. Pratama Andika, I. Agung Bayupati, N. Ayu Wirdiani, "Rancang Bangun Aplikasi Pendeteksi Tipe Dan Nilai Resistor Berbasis Android," Lontar Komputer., vol. 6, no. 1, 2015.

[9] Fitri Astutik, "Sistem Pengenalan Kualitas Ikan Gurame dengan Wavelet, PCA, Histogram HSV dan KNN," Lontar Komputer., vol. 4, no. 2, 2013.

[10] N. Ayu Wirdiani, N. Triana Anggra Emi A. A. K. Oka Sudana, "Application of Androidbased Ear Biometrics Identification," International Journal of Computer Application., vol. 172, no. 10, pp. 11-17, 2017. 